\title{
5
}

\section{Higher Education; For Free, For Everyone, For Real? Massive Open Online Courses (MOOCs) and the Responsible University: History and Enacting Rationalities for MOOC Initiatives at Three Swedish Universities}

\section{Linda Barman, Cormac McGrath, and Christian Stöhr}

\section{Barman $(\bowtie)$}

KTH Royal Institute of Technology, Stockholm, Sweden

Karolinska Institutet, Stockholm, Sweden

e-mail: lbarman@kth.se

C. McGrath

Stockholm University, Stockholm, Sweden

Karolinska Institutet, Stockholm, Sweden

e-mail: cormac.mcgrath@edu.su.se

C. Stöhr

Chalmers University of Technology, Gothenburg, Sweden

e-mail: christian.stohr@chalmers.se 


\section{Introduction}

For the past decade, universities around the world have offered a new form of online education that circumvents traditional university admission processes and provides broad and open access to knowledge from higher education institutions (HEI). These large-scale education initiatives are commonly referred to as MOOCs (Massive Open Online Courses). This chapter addresses MOOCs as an example of how universities in Sweden have responded to a "novel" (non-traditional) way of offering education with the potential of taking a broader responsibility to educate society. We acknowledge that MOOCs may create opportunities for universities to take an active role in educating society and provide affordable pathways to lifelong learning for a wider population, on a global scale. Furthermore, MOOCs potentially offer a way for universities to be accountable actors in society and could, for example, provide means to address issues of diversity and equal opportunities (Barman et al. 2018; Santos et al. 2017). Within the European Union (EU), open education initiatives such as MOOCs are regarded as important drivers of education quality, and their development is stimulated and encouraged through, for example, policy recommendations (Santos et al. 2017) and funding from EU-supported networks like EIT Health (European Institute of Innovation \& Technology) (www.eithealth.eu). Today, the higher education sector is the largest public sector in Sweden, and many different stakeholders share an interest in its responsiveness and relevance vis-à-vis societal needs, the quality in its processes and outcomes, and the accountability of the academic institutions (Sadurskis 2018; Barman 2015).

The literature has identified a number of potential benefits of MOOCs, such as extending public outreach and offering free education for all (Henningsohn et al. 2017; Stöhr et al. 2019). MOOCs, given their massive scale and the possibilities to re-use course material, are also argued by some to act as a cost-efficient way of offering higher education (e.g. Ruth 2012). Further, MOOCs could provide higher education students with the opportunity to study courses from universities other than those they are admitted to. MOOCs could be a way to combat the increasing income-related gaps affecting access to higher education which, for example, in the US, continue to increase (Haveman and Smeeding 2006). This potential affordance of MOOCs also brings into focus the option 
that they may provide a way for universities to practise responsible agency in society, taking responsibility not only for educating for domestic purposes but also demonstrating a global claim to provide education for all. In addition, responsibility with respect to MOOCs may be achieved through the introduction and utilisation of new and emerging technologies. For instance, distance or blended learning approaches create opportunities for non-traditional students, as admission policies can be changed to allow larger groups of students to attend introductory MOOC courses as a way of identifying students with an aptitude for a subject. Moreover, it may be argued that this opening up of education via MOOCs could be a way for Swedish universities to comply with the so-called third mission, which states that, in addition to research and education, universities should engage in public outreach, and the dissemination of knowledge from the university into society at large:

The mandate of higher education institutions shall include third stream activities and the provision of information about their activities, as well as ensuring that benefit is derived from their research findings. (Swedish Higher Education Act, $\$ 1$, Section 2)

As such, MOOCs may be one way for Swedish universities to extend their public outreach at a global level. Viewed through an outreach perspective, MOOCs appear to be a promising way for Nordic HEIs to embrace the notion of being a responsible stakeholder in society (Kahlroth et al. 2016; Santos et al. 2017). In doing so, MOOCs could act as a vehicle for the delivery of the United Nations Sustainable Development goal number 4, aiming to "Ensure inclusive and quality education for all and promote lifelong learning" (United Nations 2018). Consequently, MOOCs could serve universities to act responsively to the needs of the global society by extending their education offerings to a global public, disseminating their knowledge and provide free education to all.

More sceptical voices, on the other hand, may view MOOC initiatives as little more than costly sales pitches for universities to recruit top students, or even more insidiously, as a way of reinforcing colonial views of knowledge and knowing that run contrary to and risk de-legitimising local knowledge production (Deimann 2015; Bali and Sharma 2017). Those voices question the pedagogical quality of MOOCs (e.g. Vardi 
2012; Chafkin 2013). Also, the question of credentialing and quality assurance regarding institutions and MOOCs that offer higher education credits is debated. Evidently, MOOC initiatives come with several, and at times, conflicting expectations.

Universities that have developed MOOCs, as well as public debate surrounding MOOCs, have often emphasised many of the affordances outlined above under the guise of free education, anywhere, anytime, evoking near mythical connotations (Pappano 2012; Deimann 2015). Given the tradition of offering tuition-free education in Sweden, in this chapter we discuss how offering MOOCs resonates with the notion of the responsible university from the perspective of Swedish higher education. We reason about which roles MOOC initiatives may play in the Swedish higher education context by describing the response to the MOOC phenomenon in three universities: Karolinska Institutet (KI), Chalmers University of Technology (Chalmers) and KTH Royal Institute of Technology (KTH). To inform the discussion, we analysed notions of intent expressed in these three universities' formal MOOC statements, including visions, MOOC project missions, strategies and internal calls for engaging teachers. To discuss the meaning of the MOOC initiatives and the roles these may play, we juxtapose the discourses expressed in these written documentations with an adaptation of a framework by Christensen et al. (2007) on how public organisations negotiate bounded realities and how these discourses may reflect the notion of the responsible university.

The remainder of the chapter is structured as follows: After a short introduction to the history of MOOCs and its major promises that can be connected to the notion of the responsible university, we describe the emergence of MOOCs in the Swedish and the Nordic context and discuss some of the challenges for HEIs in Sweden to offer MOOCs. Finally, we discuss what role MOOC initiatives may play in the Swedish higher education (HE) context, based on a document analysis of the rationalities for offering MOOCs at three Swedish universities. This is followed by some concluding remarks about MOOCs and the responsible university in the Swedish context. 


\section{What Are MOOCs and How Have They Developed?}

The term 'MOOCs' dates back to Stephen Downes and George Siemens, who developed and ran a course known as CCK08 "Connectivism and Connectivity Knowledge” in 2008 (Siemens 2013). The 25 campus students attending the course were accompanied by 2300 online participants from around the world (Fini 2009). However, the popularisation of MOOCs is typically attributed to Peter Norvig and Sebastian Thrun's MOOC "Introduction to Artificial Intelligence" in 2011: 160,000 learners enrolled and more than 20,000 completed that course (Rodriguez 2012). A few months later, Thrun founded Udacity, the first MOOC repository, followed by Coursera, founded by Stanford professors Andrew $\mathrm{Ng}$ and Daphne Koller in April 2012, and edX, a partnership between Harvard University and MIT in May 2012.

The two MOOCs mentioned above applied very different pedagogies and served as the basis for the most established MOOC typology: cMOOCs and $x M O O C s$. cMOOC refers to the concept of connectivism that stresses the role of distributed knowledge networks. Connectivist MOOCs, such as CCK08, attempt to create many-to-many relations between learners by emphasising learner autonomy, peer-to-peer learning and social networking (Rodriguez 2013). Content is developed collaboratively by participants in smaller communities with a shared interest in a specific phenomenon (Siemens 2013) and spread through various collaborative tools, including blog posts and discussion forums. xMOOCs take a more traditional, tutorcentric approach to learning, establishing a one-to-many relationship. This typically involves a combination of video lectures and automatically graded quizzes and tests. The automated assessment and feedback allow for the inclusion of large (/massive) numbers of learners, as Norvig and Thrun's MOOC demonstrated. Teacher-learner and learner-learner interactions are non-mandatory and often reduced to reading and writing in a discussion forum. In the public discourse, the term MOOC is usually used synonymously with the xMOOC model (Moe 2015).

The New York Times named 2012 "The Year of the MOOC" (Pappano 2012). As a potential force in higher education, it was argued that MOOCs have the potential to revolutionise, but also to threaten tradi- 
tional higher education (Yuan and Powell 2013). Key advantages of MOOCs include (Huang 2015):

- an increased learner flexibility due to the asynchronous studies of a few hours per week over a shorter or longer period, such as 5-15 weeks

- global, free access enabling anyone to "learn on schedule, anytime, anywhere"

- a flexible pedagogy, allowing learners to learn at their own pace and style

- online communities for active learners

- reduced costs through scalability and repeated usage

- various functions to fit the different needs of lifelong learners.

Interest in Massive Open Online Courses has grown tremendously worldwide, and they have become a part of the international educational and education research landscape. Today (December 2018), more than 900 education institutions offer more than 11,000 MOOCs with over 101 million subscribed learners (Shah 2018). Universities are thereby not the only course providers, as companies (e.g. Microsoft and IBM) or other organisations (e.g. the Linux foundation and Amnesty International) increasingly engage in MOOC development as well. Additional MOOC providers, such as FutureLearn, were founded and the major platforms also offer MOOCs in a range of languages, such as Mandarin, Hindi, Korean, French and Spanish, to name a few.

The MOOC landscape has evolved and currently includes a broad selection of course-like offerings in various formats, such as cMOOCs, xMOOCs and mixtures of both. It also inspired the birth of similar concepts such as quasi-MOOCs (e.g. Khan Academy), extremely short Nano Open Online Courses (NOOCs), pop-up MOOCs addressing highly topical issues, as well as somewhat alternative models such as Small Private Online Courses (SPOCS). In recent years, the major MOOC providers have also encouraged universities to bundle their MOOCs into programmes. The MOOC series programmes often target professionals and include highly specialised skills training. Some providers go even further, offering a complete online master's programme, like Coursera (www. coursera.org/degree), or edX's MicroMasters, which is a series of courses at graduate level which, upon successful completion, lead to an own- 
standing professional certificate and offer a pathway to credit in a regular master's programme in the MOOC-hosting university (Stöhr 2018).

\section{MOOCs and Free Access to Education}

A fundamental idea of MOOCs is to provide easily accessible learning materials via the internet that can be free of charge. MOOCs, particularly in the early years, were seen as a way of providing access to high quality education from cutting edge researchers, to a broad audience. A major promise is thereby the provision of education to disadvantaged, underprivileged groups who are without access to established routes to higher education. In this respect, the major platform and course providers have, over the years, shared several success stories about how people with limited access to higher education have improved their lives or living conditions for their societies after gaining new knowledge via MOOCs. Such an example is the story about a small village in Colombia that gained electricity after building a generator utilising solar energy. Other examples include the establishment of a network of women in the Middle East that accessed education as a result of participating in MOOCs from their homes, or how patients have learned to understand illness and sought hospital care as a result of having attended a MOOC on urology.

MOOCs may offer HEIs ways to be responsive and address urgent societal challenges, such as the recent stream of refugees, by contributing with large-scale, accessible education (see e.g. https://kiron.ngo, Kahlroth et al. 2016). However, Swedish universities' options for taking action to meet such urgent national or global social challenges are limited. In Denmark, Norway and Finland, universities may offer and assess individuals in continuing professional development (CPD) at a cost (Kahlroth et al. 2016; Danmarks Akkrediteringsinstitution 2016). In Sweden, however, CPD is restricted by the mandate given to higher education institutions (Higher Education Ordinance, SFS: 2002:760). Currently, the Swedish system allows for contracts between companies and HEIs in the form of commissioned education, but universities cannot in other ways provide higher education credits for individuals outside the regular admission system. In addition, many Swedish universities are legal authorities and as such, are regulated by the administrative law, which makes little room for initiatives 
outside the mandate provided to legal authorities. Universities that wish to act upon and take responsibility in situations, such as the one we outlined above, need to be appointed a special mission by the government, or collaborate and seek contracts with other organisations.

\section{MOOC Credentials and Business Models}

In general, MOOCs that are "open for all" do not provide higher education credentials, but participants that fulfil course requirements may be offered certificates of participation for small handling fees or significantly reduced fees, compared to regular university tuitions. MOOC certificates thus offer proof of skills verified by universities, and according to the major course providers, MOOC certificates are proof of competence development and marketed as career advantages of interest for employers (Santos et al. 2017). However, an increasing trend is seeing MOOC providers offering learners the opportunity to transfer MOOC credits to HE credits (Danmarks Akkrediteringsinstitution 2016, www.coursera.org, www.edx. org). Since MOOC fees in general are significantly lower than regular tuition fees, there may be a strong incentive for potential higher education students to participate in and earn MOOC credits. In line with a broader marketisation of higher education, MOOC initiatives enable universities to adopt business models where student populations can be increased, thus providing revenue via tuition fees. At the same time, universities are visible on the global market and can attract new students. Initially, MOOC providers emphasised the free-for-all dimension of access while highlighting the non-profit dimensions. However, more recently providers have refined their business models to increase the numbers of paying learners. For example, recently edX changed their policy with the consequence that not all learning material is accessed for free, and courses are only open for a limited period of time unless learners pay for verified certificates.

\section{MOOCs and Inclusiveness}

In addition to access, MOOCs offer flexibility for learners on several levels. Given the online character of courses and the dominance of asynchronous learning activities, course participants are enabled to learn anywhere, 
anytime and at their own pace, fostering a global, lifelong learning approach to education. Since the beginning, the major MOOC providers require that all learning material is presented in ways that are accessible to a diverse learner population. Such demands include how material should be presented, for example, the combination of sound and texting provided in all videos, or the increased use of screen readers that aid the visually impaired to access and perceive visual material. MOOCs have the potential to meet the needs of diverse learners in various ways. However, a recent study suggests that teachers involved in MOOCs at a Swedish university held quite naive understandings of inclusiveness. One view was, for example, that by virtue of being openly accessible online, the course is in itself inclusive. Teachers with more sophisticated views on inclusive teaching still found it hard to meet the needs of various learners in practice (Barman et al. 2018). Offering education to all by granting access to online course material may create equal opportunities in theory, but questions like translation of learning material into multiple languages and the possible lack of learners' previous higher education experiences are some of the issues that arise and may be difficult to compensate. A more critical question is that of student demographics. There is considerable empirical evidence suggesting that MOOCs mostly benefit those who are already well-educated and struggle to reach disadvantaged, underprivileged groups (e.g. Emanuel 2013). One observation is that typically, MOOCs require a reasonably high degree of self-regulated learning (Littlejohn et al. 2016).

\section{MOOCs in the Swedish Context}

Sweden is well known to be a country in the forefront of technological developments, not least in the context of higher education. For example, Sweden has a long tradition of distance learning (Elf et al. 2015). However, in the European context, Sweden was neither particularly quick nor slow in its response to the global MOOC movement. Independent from the MOOC developments in the US, the first MOOC-like offerings from HEIs in Sweden date back to the beginning of the millennium and targeted a native speaking public. An early collaboration between Stockholm University and KTH (later including several HEIs) aimed to provide math courses (in 2002) to bridge the students' secondary school knowledge of 
maths with the needs of STEM (Science, Technology, Engineering and Mathematics)-oriented higher education programmes. MOOC-like initiatives primarily targeted towards secondary school pupils were also found in other Nordic countries, such as Finland, that were offering open online courses in Finnish in 2010. In Denmark, three universities partnered and offered MOOCs in English via the global platform Coursera in 2013. Today, a number of MOOCs are offered in Danish from other platforms with less global reach (Kahlroth et al. 2016). Initiatives from Iceland came later, but in 2018, a few MOOCs could be found on edX (www.edx.org). Since the global MOOC hype started, governments in the Nordic countries have in various ways taken action for enabling the universities to offer MOOCs (Kahlroth et al. 2016).

When the first course offerings from Swedish HEIs started to appear on the major global platforms in 2014, it was still unclear to what extent MOOCs could be developed and offered as part of the higher education mission. In Sweden, the initiative started with a few top-ranked researchintensive universities that usually partnered with one of the two major MOOC providers, edX and Coursera. Unlike countries such as France and Norway (Brown et al. 2015), Sweden did not develop a national strategy for addressing MOOCs. In Norway, for example, as early as 2013, a commission was set up to investigate possibilities and challenges with respect to MOOCs (NOU 2014). In Sweden, the lack of national policies and guidelines for MOOC development from HEIs was pointed out in the Swedish Higher Education Authority's report published in 2016 (Kahlroth et al. 2016). Kahlroth et al. (Ibid.) directed attention to a number of challenges related to MOOC offerings from HEIs in Sweden, such as handling of personal data utilised for learning analytics and research. Also considered was whether MOOCs could be offered via funding provided by the state, and if offering MOOCs corresponded to the mandate given to HEIs in Sweden (Ibid.). Since the beginning, the number of HEIs in Sweden that offer MOOCs for global outreach has increased, although the offerings are, to this date, quite modest. We found 60 unique courses from eight different universities in Sweden offered via the major platforms, including Coursera, edX, FutureLearn and Canvas Network between the years 2014 and 2019.

Higher education in Sweden, as in all Nordic countries, has a long tradition of being tuition-free. It has been less than a decade (since 2011) that 
non-Europeans/or non-EEC members (European Economic Community) are required to pay tuition for their university studies in Sweden. The universities in Sweden are governed by the Higher Education Act (1992:1434) and in addition, the Higher Education Ordinance (1993:100), stipulating that higher education should be non-profitable. These conditions rule out the business models used in many other countries where MOOCs are used as a means to finance, for example, teachers' engagements in public outreach. From September 1, 2018, the Higher Education Ordinance (1993:100, chapter 11) stipulates that public funding can be used to create and offer MOOCs, and that certificates can be issued upon course completion. However, the ordinance states that MOOCs are open, which means that $\mathrm{HE}$ admission processes do not apply. Consequently, MOOCs are not a part of the higher education offerings in Sweden, and hence the participants are not deemed students in higher education. The HE Ordinance legitimises HEIs in Sweden to offer MOOCs, but still there are a number of "grey areas" that remain, such as the practicalities around issuing of certificates or the validation process for recognising individual students' MOOC certificates as part of their HE studies; these issues have, in our experience, continued to create debate locally. Currently, proof of MOOC completions would follow the same validation process as other testimonials of prior learning made from practice and not be considered higher education credits. In the public debate, the MOOC offering in Sweden is strongly connected to the universities' social responsibility and an increased pressure to offer possibilities for lifelong learning (Universitetskanslerämbetet 2017). Whether the initiatives to engage in MOOCs will lead to new policy in Sweden for offering education to nonenrolled higher education students remains to be seen.

\section{Rationalities for Offering MOOCs at Three Swedish Universities}

So far, we have focused this discussion on how MOOCs may be one way for higher education institutions in general, and particularly in Sweden, to broaden its mission by educating society at large and how this reflects on HEIs as being a responsible agent. In this passage, we discuss what role 
MOOC initiatives may play in the Swedish HE context from the perspective of how three $\mathrm{HE}$ institutions have positioned their initiatives to engage in and offer MOOCs. We have chosen to inform this discussion by examining the intentions with their respective MOOC initiatives expressed by three universities, each with a strong profile on taking social responsibility in their research and education fields of medicine and health (Karolinska Institutet), and technology and engineering (Chalmers University of Technology and KTH Royal Institute of Technology). Furthermore, Karolinska Institutet was the first Swedish university to provide free, globally available MOOCs in October 2014. Between 2015 and 2019, Chalmers and KTH offered the highest number of MOOCs through the major global platforms, including two varieties of MOOC programmes: MicroMasters and the Professional Certificate programme. Our discussion about the role that MOOC initiatives may play for universities in Sweden is based on the analysis of key MOOC-related documents outlining the vision, mission and strategy at the three universities. We choose to include documents in the public domain, such as overall university strategies, and internal documents identified as being central to MOOC initiatives within each university. These include the universities' calls for teachers to engage in MOOCs and the MOOC mission or project statements. Although the overall university strategies do not address the MOOCs as a central theme, these documents were of interest as they include digital learning visions and strategies during the development of MOOCs at the respective universities (2014-2018). First, we provide a brief introduction to the universities and their respective MOOC initiatives.

\section{Karolinska Institutet (KI)}

Karolinska Institutet (KI) offers a broad range of education in medicine and health sciences at both undergraduate and graduate levels and accounts for over 40 per cent of the medical academic research conducted in Sweden. Since 1901, the Nobel Assembly at Karolinska Institutet has selected the Nobel laureates in Physiology or Medicine. In 2013, KI was the first university in Sweden to join edX as a charter member, with the 
outspoken ambition to offer MOOCs that represent a broad spectrum of KI life science education and to share the knowledge generated at KI with a broad and global audience. KI claims that the MOOCs are further expected to contribute to a commitment to quality education that can lead to an improvement of human health. To date, KI offers 12 unique MOOCs on edX. The courses run as tutored courses with staff on hand or as self-paced courses where the course activities, materials and assessments are available without active engagement from staff members.

\section{Chalmers University of Technology (Chalmers)}

Chalmers University of Technology is a research-intensive university that offers education in technology, science, shipping and architecture, with a sustainable future as its global vision. Unlike many other Swedish universities, Chalmers has the status of a private foundation university making it somewhat less dependent on Swedish regulation for public universities. Chalmers started its engagement with MOOCs in 2014. During a threeyear pilot project, eight MOOCs were produced and conducted, addressing different engineering and sustainability-related topics from introductory up to advanced level. As part of Chalmers "lifelong learning" strategy, the project was followed by a second MOOC project that aims at developing a MicroMasters programme in "Emerging Automotive Technologies." The MicroMasters programme is a series of seven MOOCs that, when completed, provides learners with a company-endorsed certificate and potential accreditation for students that are admitted through the regular system to study at Chalmers.

\section{KTH Royal Institute of Technology (KTH)}

KTH is the largest technical research and learning institution in Sweden that offers study programmes in engineering, teaching and architecture. $\mathrm{KTH}$ positions itself as an innovative European university working with industry and society in the pursuit of sustainable solutions to some of humanity's greatest challenges, such as climate change and future energy 
supply. KTH joined as a contributing member of edX in 2015 with the ambition to develop capacity for offering MOOCs with global outreach within engineering and related subjects. Up to this date, 16 unique courses and several re-runs have been developed, as well as two Professional Certificate Programmes targeting industry professionals. At KTH, the course material from several MOOCs has been transferred to the regular campus courses.

The MOOCs offered by KI, Chalmers and KTH are all in English and targeted towards the general public, professionals within certain fields, or are suitable for higher education students or even graduates at masters or doctoral levels. Table 5.1 presents a brief overview of the courses offered by the three universities, focusing on the main intended audience and levels of specialisation.

\section{MOOC and Discourses of Change}

A recurring theme in the MOOC rhetoric is the notion of global outreach (Deimann 2015). MOOCs are used to enable the universities a place in the global higher education arena, and thus provide an opportunity to market the institution and its research and education, while strengthening their profile as being socially responsible. Both these affordances could be expected to drive the MOOC initiatives at the three universities discussed here, and these rationalities are part of the universities' intentions with their respective MOOC initiatives (see overview in Table 5.2). However, by examining how the three universities express their respective notions of intent related to MOOCs, another discourse also stands out: namely, how universities are using the MOOC initiatives to drive change within each institution. To better understand the role that MOOC initiatives may play at these universities, we performed a content analysis (Graneheim and Lundman 2004) of the overall university's vision and MOOC-related mission statements, teaching and learning strategies (where MOOCs are mentioned) and internal calls related to the MOOC initiatives at KI, Chalmers and KTH. The analysis showed two very different motives where the MOOC initiatives aim for external recognition and social responsibility, but at the same time 


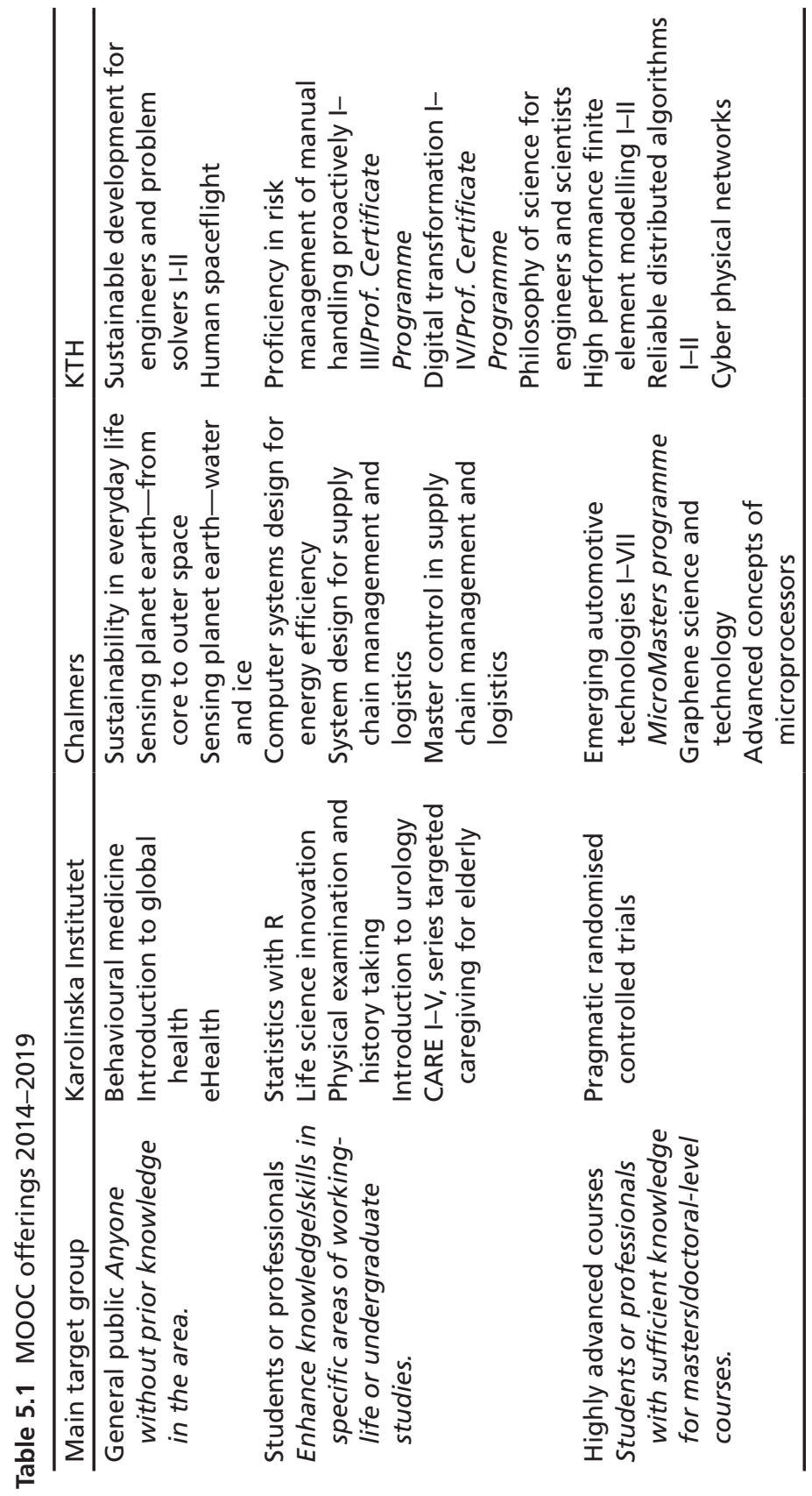


Table 5.2 MOOC rationalities at Karolinska Institutet, Chalmers and KTH

\begin{tabular}{|c|c|}
\hline $\begin{array}{l}\text { Intentions include the aim } \\
\text { to strengthen }\end{array}$ & Examples from documents \\
\hline \multicolumn{2}{|c|}{ MOOC initiatives as EXTERNAL recognition and social responsibility } \\
\hline $\begin{array}{l}\text { Marketing, including } \\
\text { display of strong research } \\
\text { areas and attracting new } \\
\text { students }\end{array}$ & $\begin{array}{l}\text { "Brand profiling where Chalmers increases its } \\
\text { visibility with regard to its vision of sustainable } \\
\text { development both through content and the } \\
\text { target groups' ability to change their } \\
\text { environment and future." (aim in the MOOC } \\
\text { project directive Chalmers) } \\
\text { "The objectives of the activities of MOOCs are to: } \\
\text { [...] contribute to making KI's educational } \\
\text { programmes and research more widely known." } \\
\text { (KI MOOC strategy) } \\
\text { "The purpose of this cooperation agreement is to } \\
\text { [...] broaden the opportunities for student } \\
\text { recruitment [...]." (KTH agreement for } \\
\text { cooperation with edX) }\end{array}$ \\
\hline $\begin{array}{l}\text { Offering of lifelong } \\
\text { learning, including } \\
\text { contribution to educate } \\
\text { professionals in defined }\end{array}$ & $\begin{array}{l}\text { "Lifelong learning. The Micromasters program } \\
\text { should provide a qualification in line with the } \\
\text { needs of at least one company." (aim in the } \\
\text { resolution MicroMasters Chalmers) }\end{array}$ \\
\hline fields & $\begin{array}{l}\text { "The objectives of the activities of MOOCs are to } \\
\text { disseminate and make available knowledge on } \\
\text { medicine and health issues globally." (KI MOOC } \\
\text { strategy) }\end{array}$ \\
\hline $\begin{array}{l}\text { Internationalisation and } \\
\text { collaborations }\end{array}$ & $\begin{array}{l}\text { "E-learning is developed in order to facilitate } \\
\text { collaboration with other leading universities and } \\
\text { to strengthen the internationalisation of KTH." } \\
\text { (Vision for e-learning KTH) } \\
\text { "The purpose of this cooperation agreement is to } \\
\text { better meet the future challenges and } \\
\text { developments through collaborations with other } \\
\text { leading member universities around the world } \\
\text { [...]." (KTH agreement for cooperation with edX) }\end{array}$ \\
\hline
\end{tabular}

MOOC initiatives as INTERNAL development of processes

Digitalisation and improved education for on-campus students
"Chalmers needs to set even more focus on quality and modernisation that meet the expectations on individualized education; to develop the pedagogy of existing courses by utilizing IT-technology from MOOCs." (MOOC project directive Chalmers)

"An important purpose of KTHs MOOC investment is to strengthen and develop the current campus education." (KTH offer) 
Table 5.2 (continued)

\begin{tabular}{|c|c|}
\hline $\begin{array}{l}\text { Intentions include the aim } \\
\text { to strengthen }\end{array}$ & Examples from documents \\
\hline $\begin{array}{l}\text { Scholarly work on flexible/ } \\
\text { scalable teaching and } \\
\text { learning }\end{array}$ & $\begin{array}{l}\text { "KTH's main goal with entering into this } \\
\text { collaboration agreement can be summarized as } \\
\text { such that KTH's MOOCs should enhance research } \\
\text { and development regarding the pedagogy of } \\
\text { online learning." (decision MOOC steering group } \\
\text { KTH) }\end{array}$ \\
\hline $\begin{array}{l}\text { Internal competence } \\
\text { development }\end{array}$ & $\begin{array}{l}\text { "Contribute to the fulfilment of KI's need of } \\
\text { knowledge within general skills such as, for } \\
\text { example, sustainable development, equal } \\
\text { conditions and ethics." (KI MOOC strategy) }\end{array}$ \\
\hline
\end{tabular}

Analysis of $\mathrm{MOOC}$ intentions expressed in the vision, mission and strategy documents and MOOC calls at Chalmers, Karolinska Institutet and KTH, 2014-2018

are intended to drive the development of various internal processes (see Table 5.2).

To understand the prevailing notions of what purpose the MOOCs may serve, we adapted Christensen et al.'s (2007) conceptual framework for explaining how public organisations are formed, maintained and governed. The framework suggests three perspectives: one instrumental (the instrumental perspective) and two institutional (the mythical and cultural perspectives) (Christensen et al. 2007). The different perspectives offer a way of understanding how public organisations negotiate a bounded rationality where the universities' statements of goals, strategies and policies are to a large extent based on a rationalist perspective, but where the enactment of these statements takes place in an ever-changing environment. The consequence of this is that the outcomes of various governing statements are highly contingent on uncontrollable and external factors, but also on internal cultural factors. As such, the instrumental and mythical perspectives provide a sort of push/pull effect on the organisation with the purpose of stipulating key performance outcomes (instrumental), while simultaneously providing rhetoric of change (mythical). In this chapter, we have modified the framework outlined above, and argue that the discourses expressed in the various 'goal documents' may serve a number of purposes, both instrumental and mythical, aimed at internal and external audiences at the same time, as shown in Table 5.2. 
At all three universities, the MOOC initiatives were initially set up as projects where an experimental approach was encouraged. The idea to experiment relates to one key element expressed in the universities' rationales for offering MOOCs, which is the discourse of change and development of internal university processes. The discourses expressed in various goal documents are used to build a narrative around the change, which is reflected in what Christensen et al. (2007) refer to as the mythical perspective. This perspective offers insight into the different notions that the universities wish to convey during the process of change, for example, the ways in which hype regarding the MOOC suggests that education is free for anyone. The mythical perspective as an analytical tool also reveals how universities position themselves as key stakeholders in society, and this may be used to comment on the purpose the university plays when engaging with broader society. Here, we argue that the rhetoric used in these narratives show the current myths that universities strive to cultivate. Universities across the globe are using similar rhetoric in the face of innovation and emerging technologies in relation to MOOCs, and one may suspect a degree of institutional isomorphism. The mythical perspective, we argue, is meant to appeal to both external and internal stakeholders. For example, when KI writes that MOOCs will: satisfy global knowledge requirements and the demand within medicine and health, and also meet national and international demand within subject-specific fields of competence which exist at KI, it is clear that $\mathrm{KI}$ is talking to an external audience, and making claims that position $\mathrm{KI}$ as a responsible actor in a global context whose offering of MOOCs may, in some capacity, contribute to addressing global needs for "knowledge requirements." Similarly, Chalmers justified the MOOC initiative among other things with the need to strengthen its trademark as a modern, progressive, technical university with a strong sustainability vision, and a global view on education and open access. The documents also point to the role of MOOCs to adapt to the changing needs of companies for customised professional education that is offered by Chalmers. In contrast, the mythical perspective also plays a role for creating meaning and rationalising MOOCs within the university.

Analysis of the documents provided input regarding how myths are brought to the fore. In relation to the three universities discussed here, 
the documents provide more clarity for internal stakeholders, such as university management or educational leaders. For example, the MOOCs are expected to fulfil a wide range of needs, including; contribute to the fulfilment of KI's need of knowledge within general skills such as, for example, sustainable development, equal conditions and ethics. Hence, this statement suggests that the choice of courses would rather be based on internal competence development needs, albeit with a strong social responsibility dimension, than the dissemination of knowledge. Further, the MOOC format and its continuous development as a way of digitalising higher education and increasing capacity for teaching scalability are intended to revolutionise, or at least develop, the internal support for digitalisation of education. For example, KTH motivates teachers to develop MOOCs in saying that it: aims to strengthen and develop the current campus education, for example in the development of digital educational resources that can be used in MOOCs as well as in regular campus courses. Chalmers makes a more visionary claim in one document that reads: MOOCs are a part of a paradigm shift, where we see education through new lenses; where concepts such as "connected learning,", individualised and customised knowledge appear as increasingly important.

All three universities connect their respective MOOC initiatives to the development of internal processes related to the digitalisation of education. For example, there is a focus on re-usability and transfer of course material created for MOOCs to campus education to ensure an efficient use of resources. In addition, engaging in MOOCs aims to increase knowledge about teaching and learning which, it could be argued, offers a form of rationalised myth (Christensen et al. 2007). In this way costs could perhaps be legitimised, but it also brings the MOOC initiatives closer to the universities' core of doing scholarly work. For example, the MOOC initiative at KTH aims to increase the knowledge of how digital learning resources can be created and used for scalable teaching-learning and educational innovation. In relation to the universities' drive for innovation, MOOCs provide unique research opportunities through detailed documentation of thousands of learners' online activities. Globally, MOOCs have fed data into the emerging fields, such as learning analytics or big data in education, with the promise to utilise massive amounts of 
click-stream data and provide insights about the unique learning paths of the participants and their performances (e.g. Zhua et al. 2018). We argue that using massive amounts of data to provide an evidence-based rationale for innovation and enhancement serves as an attractive myth to strengthen the self-perception of research-intensive universities. However, there are also opposing arguments that stress the difference between measuring learners' behaviour on platforms and facilitating learning processes that, for example, depend on the learners' intentions and needs (Ross et al. 2014; Barman et al. 2018). Apart from gaining knowledge about learners' behaviour in online environments, the MOOC initiatives are also expected to result in the possibility of adapting learning resources to individual students' needs and fostering a student-centred, personalised approach to education. For example, Chalmers states their desire to: set even more focus on quality and modernisation that meet the expectations on individualised education.

Various types of goal documents may act as specific instruments of governance, indicating the direction in which an organisation aims to strive, where the words and concepts used reverberate through the different stages of implementation. Such a rational form of instrumentalisation offers a tool for governing large-scale change initiatives or for controlling implementation of major reforms. The instrumental perspective also affords tools for quality control and accountability, where the key words used in various goal documents may then form the basis for checks and balances. In the case of MOOC, such tools for accountability could include outreach in terms of number of individuals, countries and other demographic information. In the documents we see how the instrumental perspective is articulated by pointing out the many ways in which MOOCs could be used internally within the university. For example, MOOC should be able to be used as educational modules in existing courses, but also contribute to the development of digital teaching at KI's educational programmes. Similarly, Chalmers attempts to develop the pedagogy of existing courses by utilising IT technology from MOOCs. In addition, the instrumental dimension there also includes the generation of indirect income through a strengthened trademark, higher application rates to campus programmes and possible income from administrative fees. 


\section{The MOOC Phenomenon and the Responsible University}

The public discussion about MOOCs so far has focused on the extent to which MOOCs could be a disruptive force in the higher education setting. Broadly, questions have been raised as to whether MOOCs undermine traditional pathways through higher education, thus enabling a change in the demographics where non-traditional students gain access to higher education. Concerns have also been raised that Ivy League universities may threaten the very existence of a diverse $\mathrm{HE}$ arena around the world. Others have acknowledged that MOOCs could bring about a change in the certification of higher education credit, with some examples of this already starting to appear (McKenzie 2018).

Given that the MOOCs are rather limited in content and design, and costly to develop, we argue that it is unlikely that MOOCs will replace regular higher education, at least in the near future. In this chapter, we have shown that MOOCs in the Swedish context are not considered to be higher education, even though HEIs are, since fall 2018, mandated to offer MOOCs and use state funding for that purpose. However, given that the course content in the MOOC offerings from the universities illustrated in this chapter are fairly advanced (see Table 5.1), individuals' learning outcomes gained via MOOCs can be equivalent to knowledge acquired in higher education, and sometimes even at research level. Clearly, offering MOOCs enables universities to take a social responsibility to educate on a global scale and share knowledge that contributes to sustainable development in important areas such as energy and health. In this chapter, we have outlined a number of those affordances that MOOCs potentially provide, including access to knowledge from HEIs to diversified and unprivileged groups, flexibility and customisable learning trajectories. However, from the perspective of Swedish HE, we have also identified potentially conflicting rationalities that arise between maintaining strong norms of free, state-funded education and the developing business models of the MOOC platform providers that restricts the presumed openness of MOOCs.

Besides the obvious and somewhat mythical rationale for offering MOOCs that allow universities to engage in social responsibility, we 
argue that for HEIs to be frugal it depends on how well they develop and integrate the processes and lessons learned from engaging in MOOC initiatives that will ultimately show responsibility. From the three university examples used in this chapter, we have seen how the initiatives to engage in MOOCs are, among other things, intended for capacity-building and digitalising education. Examples of such spill-over effects from MOOCs to regular university education could be to implement requirements on inclusive teaching that are currently connected to MOOCs; this would meet the needs of diverse students and benefit higher education at large. At the same time, the capacity of the universities to offer, and thereby meet, an increasing need for flexible forms of lifelong learning to private and public organisations, is also likely to be strengthened. In the long term, in order to meet the needs of graduates concerning re-skilling and up-skilling, MOOCs could facilitate collaborations by offering education between universities nationally and internationally, as well as between universities and organisations. In Sweden, this means that new policy or clarification regarding credentialing and credit transfer is needed.

In light of the changing MOOC arena, we believe claims that MOOCs are one way of universities being responsible needs further scrutiny. For example, universities might attempt to adapt to the business models currently implemented by the major MOOC providers. This may be a costefficient way of providing outreach, but it is likely to create a conflict with the ideas of openness and providing MOOCs for free, as well as contrast with strong norms in the Swedish and Nordic contexts that HEIs should provide tuition-free education. The 'openness' in MOOCs provided by the major platforms, and thus many of the worlds' most prestigious universities, seems to be on the decline. Therefore, we see the potential for the Swedish and Nordic HEIs to take responsibility in continuing to provide free access to MOOCs. This ambition seems particularly important in an era when information is easily spread and almost anyone can claim to provide facts about important issues in society. Universities in Sweden and in the Nordic context are in a position where, at least to some extent, information that is provided by universities to the public does not have to create revenue or be politically managed and, from those perspectives can be considered trustworthy. The private sector may invest in and offer online courses for skills training that is related to 
their business offerings, such as specific computer applications; whereas universities can potentially provide more advanced topics based on the idea of continuing to foster academic and critical approaches in activities for lifelong learning and global outreach. MOOCs developed at Swedish universities in the future, we speculate, are likely to offer lifelong learning opportunities for graduates and highly skilled professionals or otherwise, serve as a complement to HE studies. MOOCs based on the tradition of "folk-bildung" that rhymes with notions of public outreach and education for all, we believe, will only be offered to a limited extent.

Acknowledgements We wish to express our gratitude to colleagues at the department of Learning, KTH, and, to Cathrine Tømte at the University of Agder, as well as to the editors of this book for insightful comments on this chapter. Also, we wish to thank all participants in the Workshop series who made this book happen!

\section{References}

Bali, M. A., \& Sharma, S. (2017). Envisioning Post-Colonial MOOCs: Critiques and Ways Forward. In R. Bennett \& M. Kent (Eds.), Massive Open Online Courses and Higher Education: What Went Right, What Went Wrong and Where to Next? (pp. 26-44). New York: Routledge.

Barman, L. (2015). Striving for Autonomy. Health Sciences Teachers' Enactment of Policy. Thesis for Doctoral Degree. Stockholm: Karolinska Institutet.

Barman, L., Naimi-Akbar, I., McGrath, C., \& Weurlander, M. (2018). Engineering Teachers' Approaches to Design and Deliver Teaching in Flexible Learning Spaces. Paper presented at the Frontiers in education 2018. Fostering Innovation Through Diversity, San Jose, California, USA.

Brown, M., Costello, E., Donlon, E., \& Giolla-Mhichil, M. N. (2015). A Strategic Response to MOOCs: How One European University Is Approaching the Challenge. The International Review of Research in Open and Distributed Learning, 16(6), 98-115. https://doi.org/10.19173/irrodl. v16i6.2151.

Chafkin, M. (2013). Udacity's Sebastian Thrun, Godfather of Free Online Education, Changes Course. Tech Forecast. Retrieved December 10, 2018 , from http://www.fastcompany.com/3021473/udacity-sebastian-thrunuphill-climb. 
Christensen, T., Lægreid, P., Roness, P. G., \& Røvik, K. A. (2007). Organization Theory and the Public Sector: Instrument, Culture and Myth. Organization Theory and the Public Sector: Instrument, Culture and Myth. London: Routledge. https://doi.org/10.4324/9780203929216.

Danmarks Akkrediteringsinstitution. (2016). MOOCs kvalitet og perspektiver. Rapport, Danmarks Akkrediteringsinstitution Köpenhamn, Danmark.

Deimann, M. (2015). The Dark Side of the MOOC-A Critical Inquiry on Their Claims and Realities. Current Issues in Emerging eLearning, 2, 1. https:// scholarworks.umb.edu/ciee/vol2/iss1/3/.

EIT Health. (2018). EIT Health Home. Retrieved December 8, 2018, from https://www.eithealth.eu/.

Elf, M., Ossiannilsson, E., Neljesjö, M., \& Jansson, M. (2015). Implementation of Open Educational Resources in a Nursing Programme: Experiences and Reflections. Open Learning: The Journal of Open, Distance and e-Learning, 30(3), 252-266.

Emanuel, E. J. (2013). Online Education: MOOCs Taken by Educated Few. Nature, 503, 342-342. https://doi.org/10.1038/503342a.

Fini, A. (2009). The Technological Dimension of a Massive Open Online Course: The Case of the CCK08 Course Tools. The International Review of Research in Open and Distributed Learning, 10(5). https://doi.org/10.19173/ irrodl.v10i5.643.

Graneheim, U. H., \& Lundman, B. (2004). Qualitative Content Analysis in Nursing Research: Concepts, Procedures and Measures to Achieve Trustworthiness. Nurse Education Today, 24(2), 105-112.

Haveman, R., \& Smeeding, T. (2006). The Role of Higher Education in Social Mobility. The Future of Children, 16, 125-150.

Henningsohn, L., Dastaviz, N., Stathakarou, N., \& McGrath, C. (2017). KIUrologyX: Urology As You Like It-A Massive Open Online Course for Medical Students, Professionals, Patients, and Laypeople Alike. European Urology, 72(3), 321-322. https://doi.org/10.1016/j.eururo.2017.02.034.

Higher Education Act (SFS 1992:1434) Ministry of Research and Education. Stockholm, Sweden.

Higher Education Ordinance (SFS 1993:100). Swedish Higher Education Ordinance. Stockholm: Government offices of Sweden. (regulations on contract education SFS 2002:760. Retrieved from http://rkrattsbaser.gov.se/ sfst?bet=2002:760).

Huang, C.-L. (2015). MOOCs for Lifelong Learning. Chengren Ji Zhongshen Jiaoyu = Journal of Adult and Lifelong Education; Taipei, 25, 1-35. https://doi. org/10.3966/181880012015120025001. 
Kahlroth, M., Ejsing, C., Herjevik, M., \& Karlsson, N. (2016). Öppna nätbaserade kurser (MOOCs) i svensk högskola-Redovisning av ett regeringsuppdrag. Report 2016:1. Stockholm: Universitetskanslersämbetet.

Littlejohn, A., Hood, N., Milligan, C., \& Mustain, P. (2016). Learning in MOOCs: Motivations and Self-Regulated Learning in MOOCs. The Internet and Higher Education, 29, 40-48. https://doi.org/10.1016/j. iheduc.2015.12.003.

McKenzie, L. (2018). Online, Cheap-And Elite. Inside Higher Ed. Retrieved December 10, 2018, from https://www.insidehighered.com/digital-learning/ article/2018/03/20/analysis-shows-georgia-techs-online-masterscomputer-science.

Moe, R. (2015). The Brief \& Expansive History (and Future) of the MOOC: Why Two Divergent Models Share the Same Name. Current Issues in Emerging ELearning, 2, 1. https://scholarworks.umb.edu/ciee/vol2/iss1/2.

NOUn Norges offentlige utredninger. (2014). MOOCs for Norway New Digital Learning Methods in Higher Education. Official Norwegian Reports NOU 2014:5. Retrieved December 3, 2018, from https://www.regjeringen.no/ contentassets/ff86edace9874505a3381b5daf6848e6/en-gb/pdfs/nou 201420140005000en_pdfs.pdf.

Pappano, L. (2012). The Year of the MOOC. The New York Times. Retrieved December 10, 2018, from https://www.nytimes.com/2012/11/04/education/edlife/massive-open-online-courses-are-multiplying-at-a-rapidpace.html.

Rodriguez, C. O. (2012). MOOCs and the AI-Stanford Like Courses: Two Successful and Distinct Course Formats for Massive Open Online Courses. European Journal of Open, Distance and E-Learning. Retrieved December 10, 2018, from https://eric.ed.gov/?id=EJ982976.

Rodriguez, O. (2013). The Concept of Openness Behind c and x-MOOCs (Massive Open Online Courses). Open Praxis, 5(1), 67-73.

Ross, J., Sinclair, C., Knox, J., Bayne, S., \& Macleod, H. (2014). Teacher Experiences and Academic Identity: The Missing Components of MOOC Pedagogy. Journal of Online Learning and Teaching, 10(1), 57-69.

Ruth, S. (2012). Can MOOC's and Existing E-Learning Effciency Paradigms Help Reduce College Costs? SSRN Scholarly Paper No. ID 2086689. Rochester, NY: Social Science Research Network.

Sadurskis, A. (2018). Higher Education in Sweden. Status Report 2018:10. Stockholm: Swedish Higher Education Authority. 
Santos, A. I. d., YvesPunie, Scheller, K. (2017). Going Open: Policy Recommendations on Open Education in Europe (OpenEdu Policies). EUR—Scientific and Technical Research Reports. https://doi.org/10.2760/111707.

Shah, D. (2018). By The Numbers: MOOCS in 2018. Retrieved February 22, 2019, from https://www.class-central.com/report/mooc-stats-2018.

Siemens, G. (2013). Massive Open Online Courses: Innovation in Education? In T. McNamara, R. McGreal, W. Kinuthia, \& S. Marshall (Eds.), Open Educational Resources: Innovation, Research and Practice. Vancouver: Commonwealth of Learning and Athabasca University.

Stöhr, C. (2018). The MicroMasters Concept as Mixed Blessing-First Experiences from Developing a MOOC Program in "Emerging Automotive Technologies”. EDULEARN18 Proceedings (pp. 6572-6580). https://doi. org/10.21125/edulearn.2018.1565.

Stöhr, C., Stathakarou, N., Mueller, F., Nifakos, S., \& McGrath, C. (2019). Videos as Learning Objects in MOOCs: A Study of Specialist and NonSpecialist Participants' Video Activity in MOOCs. British Journal of Educational Technology, 50(1), 166-177.

Universitetskanslerämbetet, UKÄ. (2017). Retrieved December 10, 2018, from http://www.uka.se/om-oss/konferenser\%2D\%2Dseminarier/ konferenser\%2D\%2Dseminarier/2017-12-04-hogskoleforum.html.

United Nations. (2018). Sustainable Development Goal 4: Quality Education. Retrieved November 11, 2018, from https:/www.un.org/sustainabledevelopment/education/.

Vardi, M. Y. (2012). Will MOOCs Destroy Academia? Communications of the ACM, 55(11), 5-5. https://doi.org/10.1145/2366316.2366317.

Yuan L., \& Powell, S. (2013). MOOCs and Open Education: Implications for Higher Education, 2013. JISC CETIS white paper. Retrieved December 10, 2018, from http://publications.cetis.org.uk/2013/667.

Zhua, M., Saria, A., \& Miyoung Leeb, M. (2018). A Systematic Review of Research Methods and Topics of the Empirical MOOC Literature (2014-2016). The Internet and Higher Education, 37, 31-39. 
Open Access This chapter is licensed under the terms of the Creative Commons Attribution 4.0 International License (http://creativecommons.org/licenses/ by/4.0/), which permits use, sharing, adaptation, distribution and reproduction in any medium or format, as long as you give appropriate credit to the original author(s) and the source, provide a link to the Creative Commons licence and indicate if changes were made.

The images or other third party material in this chapter are included in the chapter's Creative Commons licence, unless indicated otherwise in a credit line to the material. If material is not included in the chapter's Creative Commons licence and your intended use is not permitted by statutory regulation or exceeds the permitted use, you will need to obtain permission directly from the copyright holder.

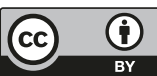

